\title{
A Virtual Reconstruction Methodology for Archaeological Heritage in East Asia - Practical Experience from the Re-relic Program in China
}

\author{
HE Yan, GAO Ming, SHANG Jin \\ Department of Architecture and Urban Heritage, Tsinghua Urban Planning \& Design Institute \\ (THUPDI), Beijing, China.
}

\begin{abstract}
Resumen
El este de Asia se caracteriza tanto por su abundancia en patrimonio arqueológico como por su diversidad metodológica a la hora de llevar a cabo reconstrucciones y representaciones de dicho patrimonio. El programa Re-reliquia en China reconoce la singularidad del patrimonio arqueológico en el este de Asia y ha desarrollado una metodología adaptada para la reconstrucción virtual, científicamente sólida para la interpretación pública. El examen teórico y la experiencia de campo en los próximos años contribuirán a la comprensión global del valor y la técnica en la reconstrucción virtual, al prestar atención a los principios de la Carta de Sevilla.
\end{abstract}

Palabras Clave: PATRIMONIO ARQUEOLÓGICO; ASLA DEL ESTE, CARTA DE SEVILLA; PROGRAMA DE RECONSTRUCCIÓN VIRTUAL RE-RELIQULA.

\begin{abstract}
There is as much abundance of archaeological heritage in East Asia as there is diversity in the methodology for its reconstruction and representation. The Re-relic program in China recognizes the uniqueness of archaeological heritage in East Asia and has developed a tailored virtual reconstruction methodology that is both scientifically robust and popular for public interpretation. The theoretical consideration and field experience over the years shall contribute to the global understanding of the value and technique in virtual reconstruction, while testifying to the very principles of Seville Charter.
\end{abstract}

Key words: ARCHAEOLOGICAL HERITAGE; EAST ASLA; SEVILLE CHARTER; RE-RELIC PROGRAM; VIRTUAL CONSTRUCTION.

\section{EASt Asian ARChaEOlogical Site}

\subsection{Introduction to East Asian Architecture}

East Asia can be considered a common culture mellenia ago. As early as 200BC, there was already frequent communication among what is today China, Korea and Japan in terms of culture, economy, science, language and religion. Under the prevailing influence from the leading culture of China, the building technique in East
Asia gradually merged into one system, which has cast a lasting effect on architecture over the centuries and to the modern day. Architecture in East Asia maintained it major characteristic of a timber frame that take the place of load bearing walls in a stone builing, giving it a delicate appearance. Although there is a great diversity in detail and style, the main structural system is identical. It is for this reason that there is an established common ground for archaeology and architectural history in East Asia. 


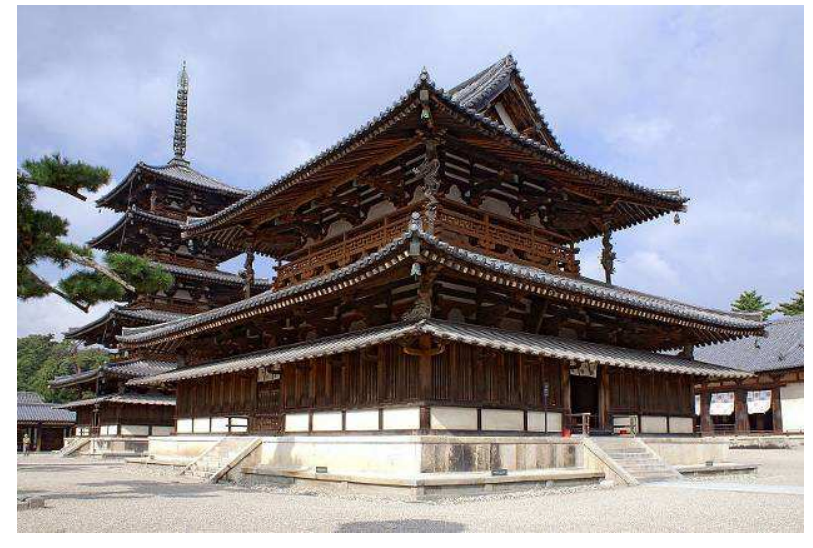

Figure 1. Horyuji, ca. 711, earliest surviving evidence of architectural features in East Asia, Nara, Japan

\subsection{Common Characteristics in East Asian Architecture: Timber-framed Structure}

Although the building types in East Asian range from Palace, Temple, Housing, Garden, Tomb, Pagoda to Grotto, the influence of a timberframed system is at all their foundation. Generally, a timber-framed building is consisted of three parts: a stone foundation at the bottom, a wooden frame that stands upon it, and a tile roof above. The three parts are systematically integrated by an architectural methodology that gradually developed and summarised into treatises and building codes, such the Yingzao Fashi (State Building Standards, ca. 1100) in China, and Shyomei (Guidance for Masters, ca. 1605) in Japan.

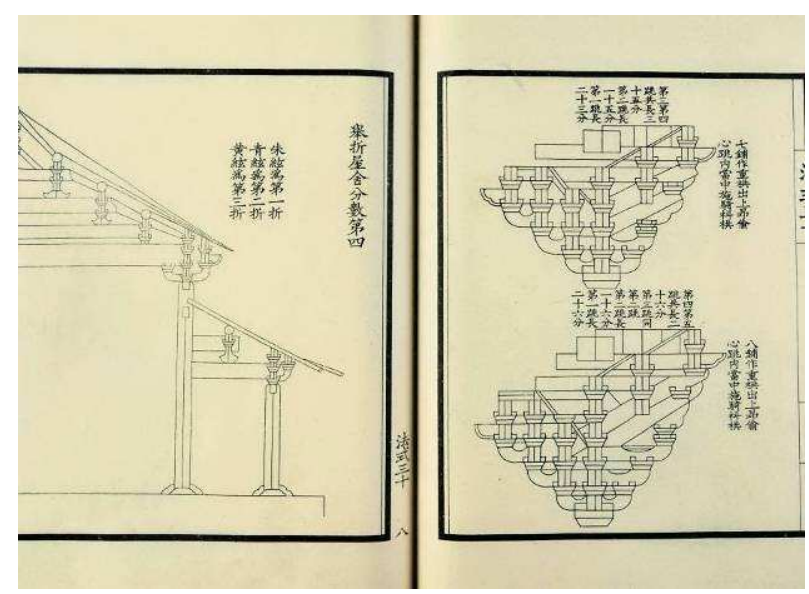

Figure 2. Yingzao Fashi, ca. 1100, brackets as the modular system for the building, Northen Song Dynasty, China
Such technique, which successfully came down to this day, is still widely practised. In 2009, the Traditional Architectural Craftsmanship for Timber-framed Structures from China was inscribed in the Representative List of the Intangible Cultural Heritage of Humanity, again demonstrating an interconnected culture in East Asia.

\subsection{Unique Features of Archaeological Sites in East Asia}

Besides the convenience in construction, timer structure is also known for its vulnerability to worm, fire, and moisture. Horyuji in Japan has been repaired and reassembled no less than four times until the 20th century and this is how it managed to survive. However, buildings cease to be reconstructed when maintenance is interrupted due to wars, social upheaval or econmical turmoil. Because of this, a large amount of structure couldn't make it to this day, and most of the time only the stone foundation is left.

Although the main body scarcely remains, the archaeological site, combined with a solid theoretical foundation of research on builiding codes, contains a lot of information for interpretation, which provides the solid ground for rigorous reconstruction.

\subsection{Contemporary Practice in the Conservation and Utilization of Archaeological Site in East Asia}

It is common to publish the result from archaeological research in the form of representations. After proper treatment to the site, many types of representation is performed to show to the public what has been learnt. This includes structural shelters where the site can be both protected and represented, or simulations prepared to capture the shape of pillars on the foundation. Neither the original nor simulated representation is good enough for people to understand, where as in the West, the archaeological site of stone and brick structure is 
relatively easy to interpret. So for archaeological sites of timber-framed structures in East Asia:

a) The archaeological site proper is what actually carrying authentic historical information, but what is inherently connected with it is no longer visible;

b) Preserving the site itself is insufficient for public understanding who lacks adequate knowledge to interpret it;

In some cases, the reconstruction is done to a full level. The Anapji pond and its surroundings (originally built in 674AD) within the national park in South Korea is completely rebuilt according to archaeological findings in 1974. The entire garden, fresh with new material, is applauded as the symbol to historical glory and becomes a tourist attraction.

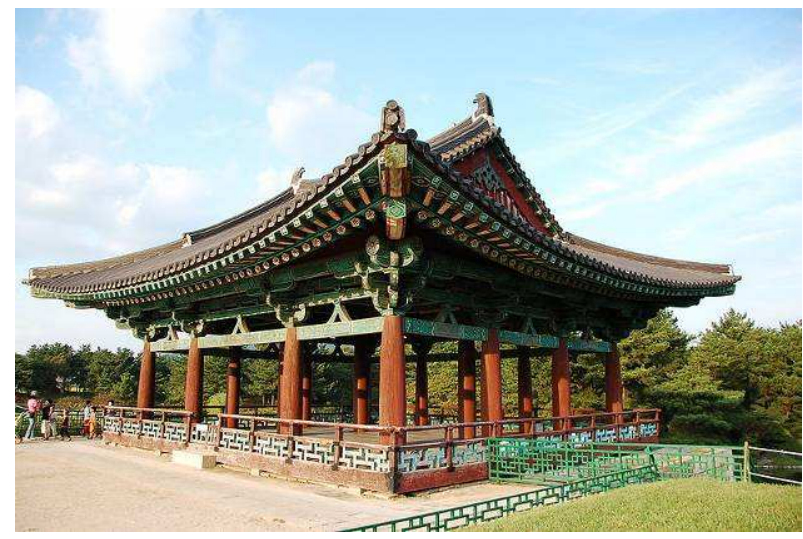

Figure 3. On-site Reconstruction of a Pavilion at Anapji Pond, ca. 674, Gyeongju National Park, South Korea

Again, in 1998, Surakumon (Gate of the Vermilion Bird) in Nara, Japan was reconstructed in a similar vein, using historical archive and relevant buildings for reference.

Although highly controversial to the Authenticity principle in international charters, such methodology is very popular in East Asia. Regardless of probably critisim, the pragamtical considerations is that a physical reconstruction may intervene the site to a large extent, but it can also be reconciled with historical philosophy of a rebirth, thus reviving the tradition.
However it may be justified in East Asia, the conflict with common sense in heritage conservation should be properly dealt with, so that a greater consensus be built for the career of conservation in the world.

\section{COMMITMENT AND OBJECTIVE OF THE $\boldsymbol{R} E-R E L I C$ PROGRAM IN CHINA}

\subsection{Initiative and Philosophy}

To address these specifice issues for the archaeological sites of perished timber-framed structures, a professional team was built with the tilte Re-relic, implying the purpose of the group to reconstruct from relics and represent what it implies.

To distinguish itself from previous practices, the Re-relic program deliberately chose virtual reconstruction as the principal measure for the following advantages:

a) The international principle of least intervention to the archaeological site is duely respected;

b) A virtual reconstruction is capable of showing all the detailed information enough, with multiple hypotheses for discussion which demonstrates the scholarly rigor.

c) The output can be disseminated in many possible ways, thus providing maximum public participation;

\subsection{Objective}

From the above consideration, the Re-relic program has made its objective to: comprehensively conserve and represent heritage to support academic research, archaeological excavation, conservation projects, regular management and public participation with a multitude of traditional and modern technological measures. To achieve this, a combined effort of architectural historians, 
heritage conservators, archaeologists, computer scientists and IT experts will be required.

With established principles for the virtual reconstruction of timber-framed structures, the program needs an actual case to implement and verify the validity of the methodology.

\section{Framework OF THE VIRTUAL RECONSTRUCTION OF YUANMINGYUAN}

\subsection{History of Yuanmingyuan}

Yuanmingyuan, known in history as the "Garden of Gardens", is an imperial garden dating back to 1707 , and continuously enlarged over 150 years. It is a living museum of the state-of-art gardening art in China. In 1860, Yuanmingyuan was almost destroyed in foreign warfare and never rebuilt since.

These unique features of Yuanmingyuan has made it a perfect choice for a pilot program to realise the purpose of Re-relic program.

\subsection{Fundamental Reconstruction}

\section{Research}

for

For the start, the virtual reconstruction of Yuanmingyuan must be as rigorous as possible, given the large amount of research already accumulated among archaeologists and architectural historians over decades. To ensure maxium validity, the program first elicited a heirarchy of the different levels of fidelity in evidences:

a) Archaeological Survey: Current condition of the archaeological remains is of primary importance both in terms of heritage conservation and the basis for virtual reconstruction. Given the fact that the whole building is an integrated design, any part can be of great significance. Therefore, even the smallest component such as broken tile must be collected and documented.

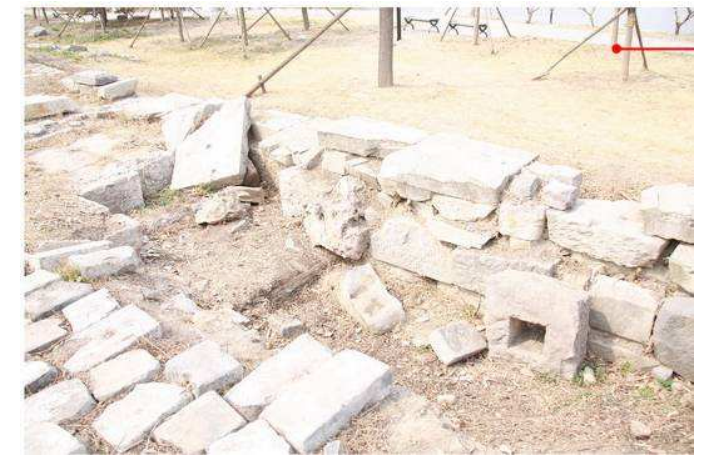

Figure 4. Current Condition of Jiuzhouqingyan

b) Historical Photos: Although photography was introduced to China rather late, the historical information that photos provide is only second to the physical remains if it is available.

c) Historical Archive: The imperial garden is also known for an abundance of official document concerning architectural design. Yangshi Lei Archive, inscribed in Memory of the World Register in 2007, is crucial for the reconstruction in that it keeps a scrupulous record of the last details of the buildings in Yuanmingyuan, most of the time when a major repair or reconstruction is implemented. It includes both scaled drawings from paints and textual records likes intentories. Even though the collection is scattered around the world, and some only survive in fragments, it is the most reliable document.

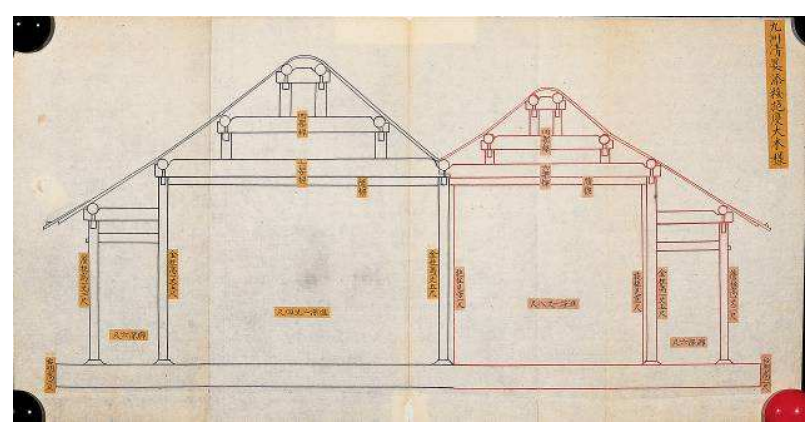

Figure 5. Yangshi Lei Archive of a Building in Jiuzhouqingyan; the Height and Diameters are Marked with Text Boxes in Yellow 
d) Artistic Paintings: The emperors had commissioned series of paintings for Yuanmingyuan at times, such as the Forty Scens of Yuanmingyuan. The artistic rendering of a site shows many details not always avaible in 2D depictions, and its validity proved by comparison to archaeological research. However, the size and proportion of components are not as exact as is recorded in drawings.

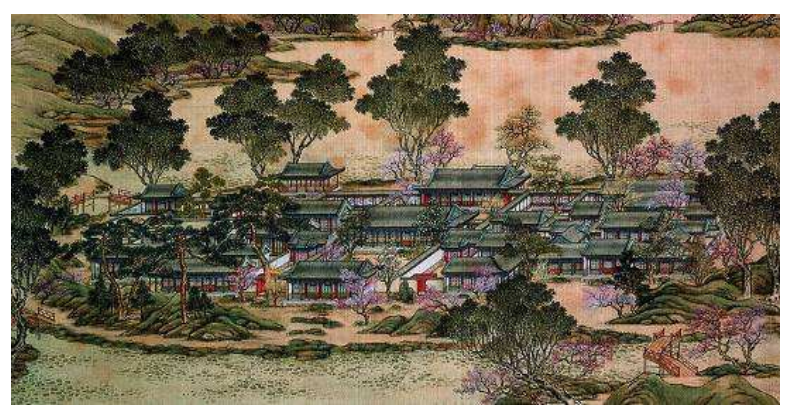

Figure 6. Silk Painting of Jiuzhouqingyan

e) Historical Literature:

Literature and poem ranks last in credibility. Although its contribution might be minor, they are enormous in number.

\subsection{Reconstruction Schemes}

a) Master Plan and Divisions of Different Periods: Having the vast span of time and area in mind, the Re-relic program divides the entire history into 13 periods, each with its specific evidences. Considering the spatial layout, the garden is further split into 110 tempo-spatial units to be individually reconstructed.

b) Specific Drawing Codes: With comprehensive research, a special drawing code is developed and circulated among all team members, so that the output is compatible for everyone.

c) Individual Buildings: All reconstruction must specify the evidence used, and according to the credit they contribute, an authenticity rating is determined for each work. Besides, all CAD drawings must be marked with the historical period of the reconstructed structure while also showing changes in the landscape. In case of conflicting evidences exist, multiple proposals must be produced and judged by open discussion.
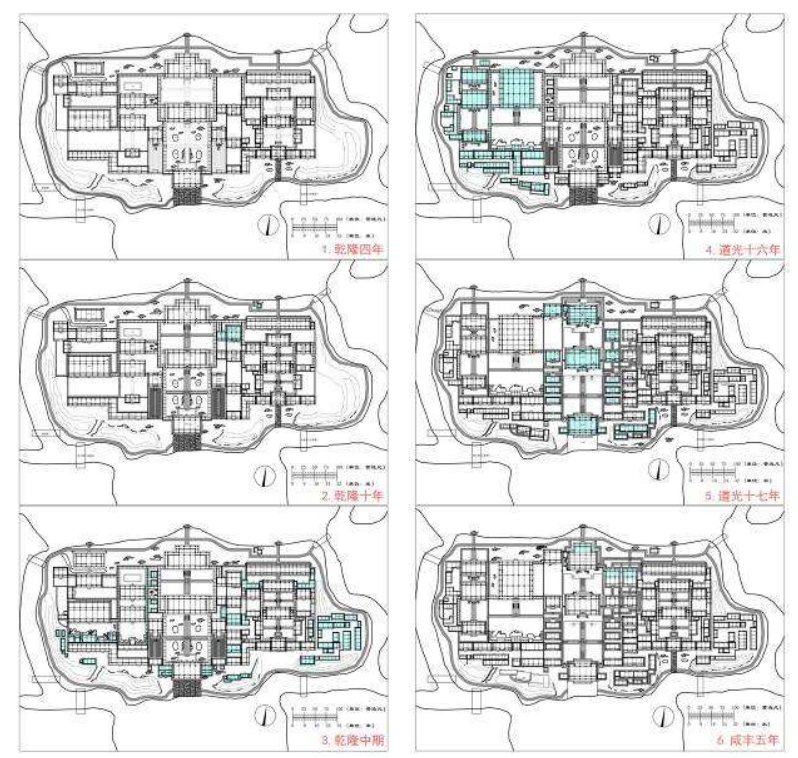

Figure 7. CAD Drawings of Jiuzhouqingyan at 6 Different Periods, with Changes Marked in Cyan

d) Modeling and Rendering: Based on the CAD drawing, the structure is translated into 3D form, again keeping periodical informations in different strata. The architectural elements, based on well grounded research, are given realistic textures from buildings that survive with identical features. Even the sculpture around the building is reconstructed from similar existant models. The surrounding landscape and vegetation is also reconstructed based on historical records. All these together contribute to a maximum level of validity in reconstruction as well as realism in visual rendering. 


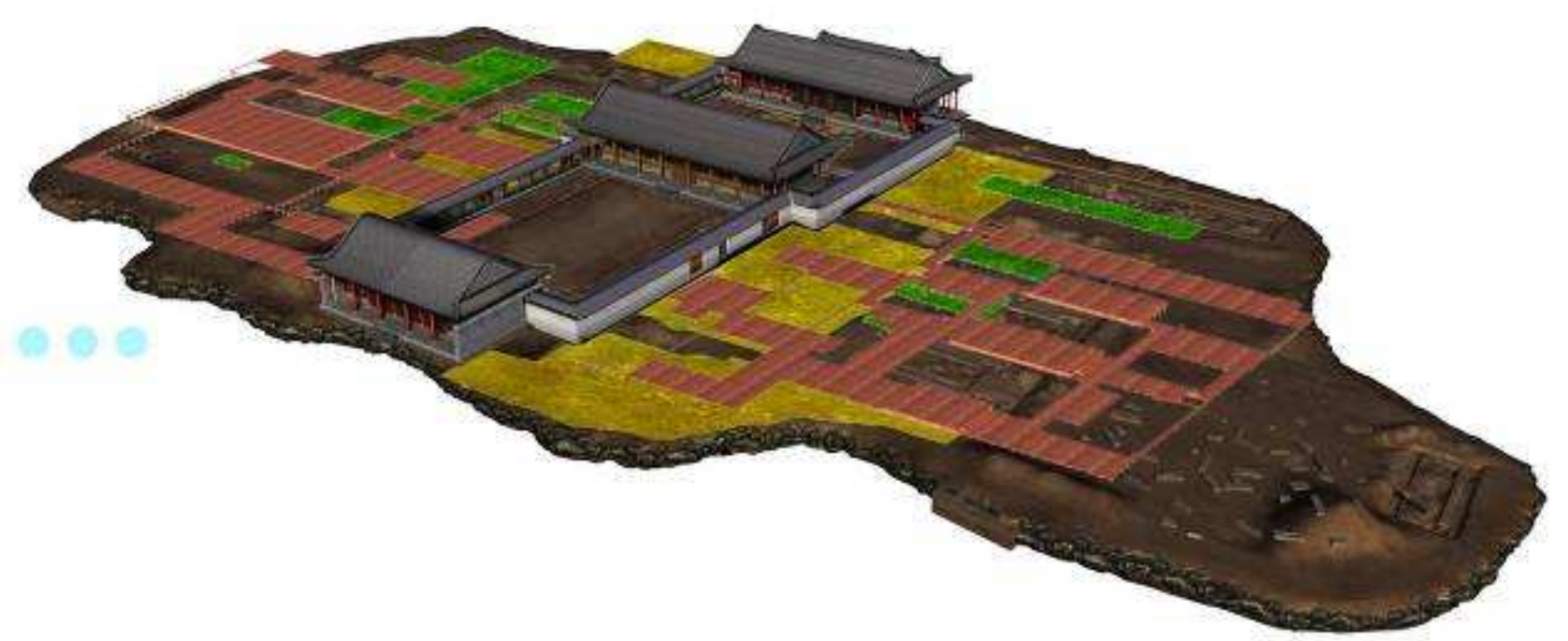

Figure 8. 3D rendering of Reconstructed Jiuzhouqingyan; Foundations at Various Periods are Marked with Different Colors
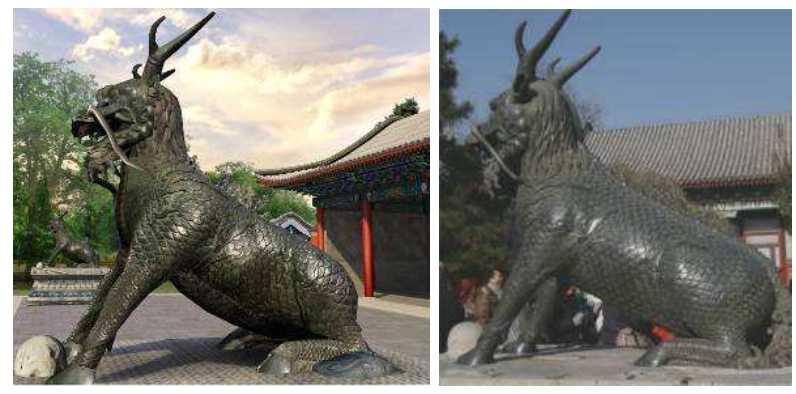

Figure 9. Reference Sculpture Captured for Reconstruction

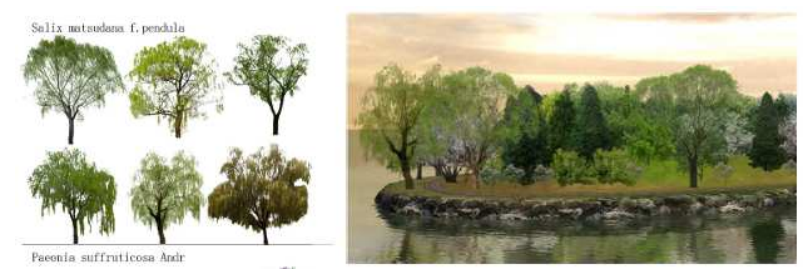

Figure 10. Vegetation Used in Reconstructed Landscape

e) Review and Transparency: The final output is then brought to an interanl meeting, and checked against each evidence used. After it get approved, the result is again published on the web for wider discussion. Whenever there is a valid feedback, the model is revised.

\subsection{Virtual Reconstruction for Participation}

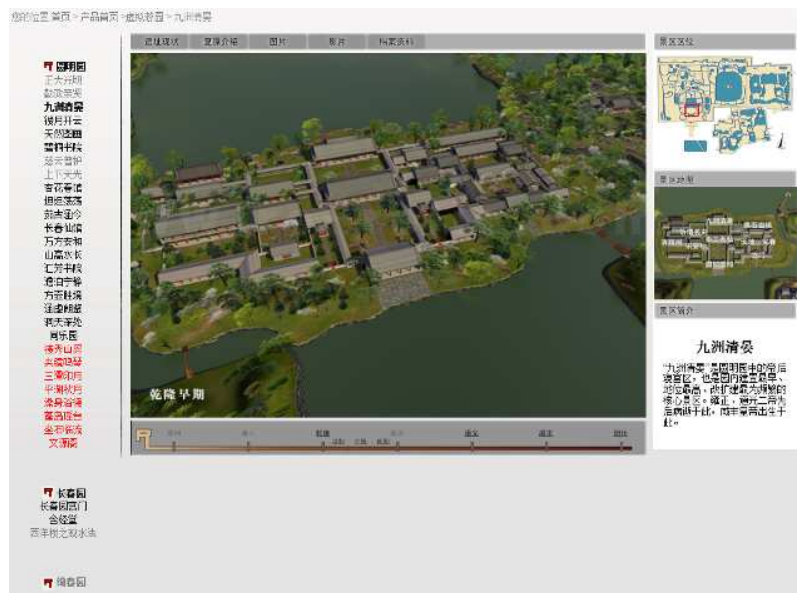

Figure 11. Re-relic Website, Showing

Jiuzhouqingyan where Visitors can Make

Comments

With the advantage of virtual models, the result of reconstruction can be published in a variety of ways including videoes, panoramas, and renderings on the network and microblogs for a greater audience. This cutting edge technology brings archaeoloy to the public in an unprecedented close distance to the good of heritage interpretation and education. 


\section{Comparison to the Principles of SEVILLE CHARTER}

The Yuanmingyuan framework is a comprehensive model for the virtual reconstruction of timber-framed structure in East Asia. Comparison with the principles of Seville Charter shows many common characteristics.

\subsection{Objectives}

The Yuanmingyuan process shares with the Charter the aim to improve research in related disciplines. They both champion the application of digital methods and value the provision of an assessment for the quality of reconstruction. A guideline for public interpretation is also what the final output is intended.

\subsection{Principles}

The similarities in principles deserves further discussion. The Yuanmingyuan program enbraces interdisciplinarity and started a new model for cooperation among architectural historians and other professionals (article 1.1). Complementarity (3.3) is a critical factor for timber-framed structure in East Asia since the major of the building is lost and virtual reconstruction is the optimum choice. The
Authenticity Rating (4.2) is an outstanding feature and respects Historical Rigour (5.2) along with the landscape reconstructed (5.3). Scientific Transparency (7.1) makes the whole endeavor a worthy campaign for the academia.

\subsection{Contribution of the Re-relic program}

The Construction Technique of Traditional Timber-framed Structure is at the very core of the entire program. The team recognizes the significance of a continued implementation of intangible heritage and deliberately applies it in a virtual manner. The inheritance of such knowledge deserve special attention where the archaeological remains are insufficient for a greater understanding of cultural heritage.

\section{Conclusion}

It is inspiring to know there is much commonality between East Asia and Europe in the rationale of virtual reconstruction. With experiences from on-going projects which is specially concerned with timber-framed structures, an international charter that covers both may be expected in the future. It shall incorporate the intangible heritage of the construction technique brought back to life in the digitgal age.

\section{ACKNOWLEDGEMENTS}

Professor Guo Daiheng has given invaluable guidance for the Re-relic program and deserves all the gratitude. For historical archive, Palace Museum, the State First Historical Archive, and Tsinghua University have provided generous help. The authors would also like to thank Yuanmingyuan Administration for its assistance throughout the process of archaeological work.

\section{REFERENCES}

GUO DAIHENG et al. (2002): Chinese Architecture, Yale University Press.

HE, Yan (2011): "Re-relic/Yuanminguan: An Effective Practice in Virtual Restoration and Visual Representaion of Cultural Heritage", in CIPA symposium proceedings 2011.

LIANG SSU CHENG, (1984): Chinese Architecture, A Pictorial History, MIT Press, Cambridge, Massachusetts.

LOPEZ-MENCHERO, V.M. et al. (2011): “The Principles of the Seville Charter", in CIPA symposium proceedings 2011. 